\title{
Consideration of transport logistics hubs in freight transport demand models
}

\author{
Stefan Huber ${ }^{1}$ - Jens Klauenberg ${ }^{1}$ - Carina Thaller $^{2}$
}

Received: 9 April 2014 / Accepted: 7 September 2015 / Published online: 28 September 2015

(C) The Author(s) 2015. This article is published with open access at SpringerLink.com

\begin{abstract}
Introduction The increasing importance of logistics and its effects on transportation processes have been considered in freight transport demand modelling by new model developments incorporating several logistics aspects. However, transport logistics hubs - hubs without storage function that are primarily used for transhipment - seem to be not considered adequately in most freight models although they are crucial for freight transport. Currently it is not apparent which models do consider transport logistics hubs and how they do. The aim of this article is, therefore, to review how transport logistics hubs are considered in freight transport demand models and to discuss remaining gaps and challenges.

Methods Based on an extensive literature review a broad and internationally oriented analysis of transport models has been conducted. More than 100 models were examined regarding their consideration of logistics in general and transport logistics hubs in particular.

Results The article points out the major importance of transport logistics hubs within freight transport and, thus, underpins the fact that they should also be considered sufficiently in freight demand models. It reveals that there are numerous models in application worldwide and that most of these models do not consider logistics or hubs. Only few models integrate logistics hubs, in general, and transport logistics
\end{abstract}

Stefan Huber

stefan.huber@dlr.de

1 DLR - Deutsches Zentrum für Luft- und Raumfahrt (German Aerospace Centre), Institute of Transport Research, Rutherfordstr. 2, 12489 Berlin, Germany

2 ITL - Institut für Transportlogistik (Institute of Transport Logistics), Technical University Dortmund, Leonhard-Euler-Str. 2, 44227 Dortmund, Germany hubs in particular. Furthermore, the consideration of transport logistics hubs within these models differs quantitatively (number and types of hubs) but also qualitatively (detail of hub integration) - also depending on model properties (e.g., scale of analysis, resolution or level of aggregation).

Conclusions Within freight transport processes, transport logistics hubs gained growing empirical significance in the recent past. This implies a major relevance to consider them in demand modelling, too. However, the article reveals that the integration of transport logistics hubs lags behind their empirical significance and that there are certain restrictions which hamper an adequate integration. The potential of many models is limited by reason of data availability. The lack of detailed data remains a major challenge that is, frankly, not new to the freight modelling community. Closing this data gap will help to consider transport hubs adequately and, thus, increase accuracy of models which would enable policy decision-makers to come to more effective decisions.

Keywords Freight transport - Transport demand modelling · Transport logistics hubs

\section{Introduction}

The economy is impacting the transport sector and vice versa [29]. As a result, detecting changes and forecasting future freight flows and freight transport demand is a task of great importance. In order to analyse and describe the relationship between the economy and transport, and in order to support planning and decision-making regarding e.g., transport policies, there is a need for accurate and efficient methods and tools because implementing and adjusting is not just straight forward [32]. Efficient tools are needed to support effective decision making [4]. Beside using qualitative methods to 
forecast future developments (see e.g., $[18,28]$ ) or estimate policy impacts, freight transport demand models are powerful tools to tackle this challenge. Thus, the final goal of such models is to enable decision makers to evaluate freight transport policies and correlated effects on the transport system [42].

Changes in freight transport are mainly driven by logistics concepts (e.g., sourcing, consolidation and distribution of goods). Logistics thereby has always been a main topic and revived in recent freight modelling. In the past, most models were lacking logistics aspects and until a few years ago there were only some models taking into account logistics. Since then logistics has found its way into models to a greater extent (see e.g., $[14,15])$.

Goods transport is increasingly managed and handled by transport logistics hubs. In Germany, for instance, nearly two billion tons are handled in terminals and warehouses each year and related operations account for around $10 \%$ of the logistics market turnover. Beside large transport logistics hubs like seaports or airports there is a big number of smaller but very important logistics transport hubs like these of freight forwarding networks, which handle around 200 million shipments each year [23]. These data underpin the importance of transport logistics hubs within the transport process. Their empirical significance, therefore, constitutes the relevance to integrate hub related transport processes in demand modelling because such integration ensures higher accuracy and more realistic sensitivity in order to assess policy measures related to logistics.

However, it is currently not clear whether and how transport logistics hubs are considered in transport demand models. Do models in application integrate these hubs adequately and, if not, what are the remaining challenges for an adequate consideration then? Thus, the scholarly contribution of the paper is to show how these special types of hubs (transport logistics hubs) are currently integrated in freight transport demand models in application and to discuss remaining gaps and challenges.

Therefore, an extensive literature review and analysis of international sources was conducted. More than 100 models were examined regarding their consideration of logistics in general and transport logistics hubs in particular. Although models were analysed covering regions around the world, most models integrating logistics and logistics hubs were identified in the U.S. and Europe. Furthermore, the paper will present supplemental data requirements in order to integrate transport logistics hubs adequately.

First of all, the article will briefly describe the importance of logistics and its development before characterizing logistics hubs and pointing out their importance in the transport system. Since logistics and logistics hubs occur in different models with different characteristics which determine the integration, a brief overview of the models and their characteristics is given in the subsequent chapter in order to provide a better placement. Finally, the main part concentrates on the integration of logistics and transport logistics hubs in existing models. Therefore, the most interesting models in use will be presented. Fundamental results, remaining challenges and new requirements concerning the integration of logistics hubs will be discussed afterwards. A conclusion will close the paper.

\section{Logistics and logistics hubs}

Logistics has become more complex and increasingly important in recent decades and is now as important in companies as traditional divisions like finance, production or marketing. Logistics is defined as the process of planning, implementing, and controlling procedures for the efficient and effective transportation and storage of goods including services and related information conforming to customer requirements. It covers the whole transport chain from the point of production to the point of consumption and includes inbound, outbound, internal, and external movements [48]. The transport from the point of origin to the point of destination is influenced by logistics and related decisions. Current developments in logistics are driven by global economic mega-trends. These trends are mainly globalization, the development and introduction of new information technologies, environmental protection as well as quality and time-based competition. Originating in the initial optimization of well-defined functions, logistics developed into the optimization of cross-functional activities and processes and, furthermore, includes value chains through design and optimization of global networks today ([24]; [2]). Accompanying this evolution, strategies and concepts of logistics have had a dominant influence on freight transportation.

Within transport logistics, logistics hubs hold a significant role today and this significance - especially regarding management and handling - still increases [20]. The logistics market volume in Germany, for example, is around 223 million EUR ( $23 \%$ of European market) and accounts for about $8 \%$ of gross value added in Germany. Terminal and warehousing operations account for nearly $10 \%$ of the logistics market in Germany and nearly two billion tons are handled in terminals and warehouses each year [23]. However, it is not only the large transport logistics hubs (seaports, public inland ports, or airports) which often act as major gateways for import and export of goods that are of major importance. There is also a big number of smaller but just as important logistics hubs like transport logistics hubs of freight forwarding networks. For the 14 networks in Germany, for instance, there are more than 900 locations (hubs) which are used for transhipment. Their turnover is around 50 million tons and 200 million shipments each year [23]. 
Figure 1 shows exemplarily the complexity of freight forwarding networks for one concrete network with all its possible connections between 40 logistics hubs in Germany (main runs on the left; local distributions tours on the right). The figure points out the vast spatial relevance of transport logistics hubs within freight transport. Especially in combination with the numbers mentioned above, it becomes apparent that transport logistics hubs are of particular significance for freight transportation. Thus, integrating transport logistics hubs turns out as an important element in demand modelling.

Logistics hubs are generally defined as linking points infrastructure facilities and nodal points - in logistics networks. They serve primarily as transhipment points for flows of goods. Accordingly, there is not only storage activity but also processes of ordering, bundling and unbundling $[25,38]$.

The variety of logistics hubs - each with its own and specific characteristics - hampers an explicit assignment of hubs to specific a type and class. In order to enable a typification, however, a simplistic differentiation is very often made on the basis of a spatial or functional analysis $[8,14,37]$. The following examples will illustrate the possible differentiation: A spatial differentiation can be made according to the spatial level (micro, meso, macro), for instance. Therefore, a transport logistics hub can be defined as hub (micro level) as well as a sea port (macro level). Regarding the functional differentiation, logistics hubs may consist of individual modules (e.g., single shipping facility) or several modules (intermodal terminal with rail freight centre and freight forwarders). Following from this, a plurality of hubs may be identified $[19,38]$.

However, these examples illustrate only two possibilities to differentiate logistics hubs. A very basic but fundamental differentiation of logistics hubs can be found in dividing logistics hubs into transport logistics hubs and distribution logistics hubs, because they fundamentally differ in numerous characteristics (see Table 1). We refer to this differentiation of logistics hubs in the rest of the paper, because the differentiation represents a very basic but reasonable method to distinguish logistics hubs in a functional and consistent way.

Distribution logistics hubs are hubs holding inventories, where goods can be stored for a longer period of time. These types of hubs usually link few sources with many sinks. Central or regional warehouses are examples of this type.

In contrast, transport logistics hubs do not have a storage function. Although there may be a certain buffer capacity due to the transhipment process, this buffer is a kind of side effect and a subordinate of the actual main function - the transhipment of goods. Transport logistics hubs usually connect many sources with many sinks. Examples for this type of hub can be found in locations of forwarding companies, combined transport terminals, airports and railroad transfer stations [19, 38, 44].
This differentiation of logistics hubs in transport logistics hubs on the one side and distribution logistics hubs on the other is fundamental in terms of freight transport demand modelling, because attracted goods and transports operated at these hubs differ significantly.

As chapter 4 will reveal, national transport demand models currently in use do not consider both types of hubs likewise. In most cases transport logistics hubs are not integrated into modelling in an adequate way. In order to assess existing approaches relating to their integration, a brief overview of models and their classification is given in the next chapter. This is crucial because model properties, which may differ significantly due a models' objective, have a great influence on the integration of logistics and transport logistics hubs.

\section{Overview of freight transport demand models}

There is a variety of freight transport demand models ${ }^{1}$ throughout the world (more than 100 different models). De Jong et al. [14] name 65 transport demand models for freight transport and 29 models coupled with passenger transport solely for Europe. The differing intentions of the national freight models and their resulting characteristics bear a crucial influence on whether and to what extent logistical aspects and transport logistics hubs can be considered in these models.

The models themselves can be divided into different categories based on their properties. Common classifications refer to their spatial resolution, scale of analysis, and depth of aggregation, variable measured or modelling method. Further explanations of these categories are presented in Table 2 [30]. In addition, there are other characteristics in order to differentiate models going beyond these main categories. Further examples can be found in their characterization due to their application, transport modes used, etc. (see [15]).

All these properties influence a models' level of detail significantly and, therefore, the consideration and detail of the integration of transport logistics hubs. Accordingly, model characteristics play a vital role in answering the question of which hubs can be considered and to what extent. Therefore, possibilities of hub differentiation vary - the possibilities vary widely e.g., comparing disaggregated microscopic models with models of macroscopic scale working with highly aggregated data.

Table 2 illustrates that there is a variety of different types of models. Nevertheless, most approaches follow the classical four-step procedure. In this manner, commodity-specific production and attraction rates of zones are calculated in a first step (freight generation). Input-output models are usually used in this step. In a second step (freight distribution) the

\footnotetext{
${ }^{1}$ For the sake of clarity, the term "model" refers to models in application, here (e.g., national freight models).
} 


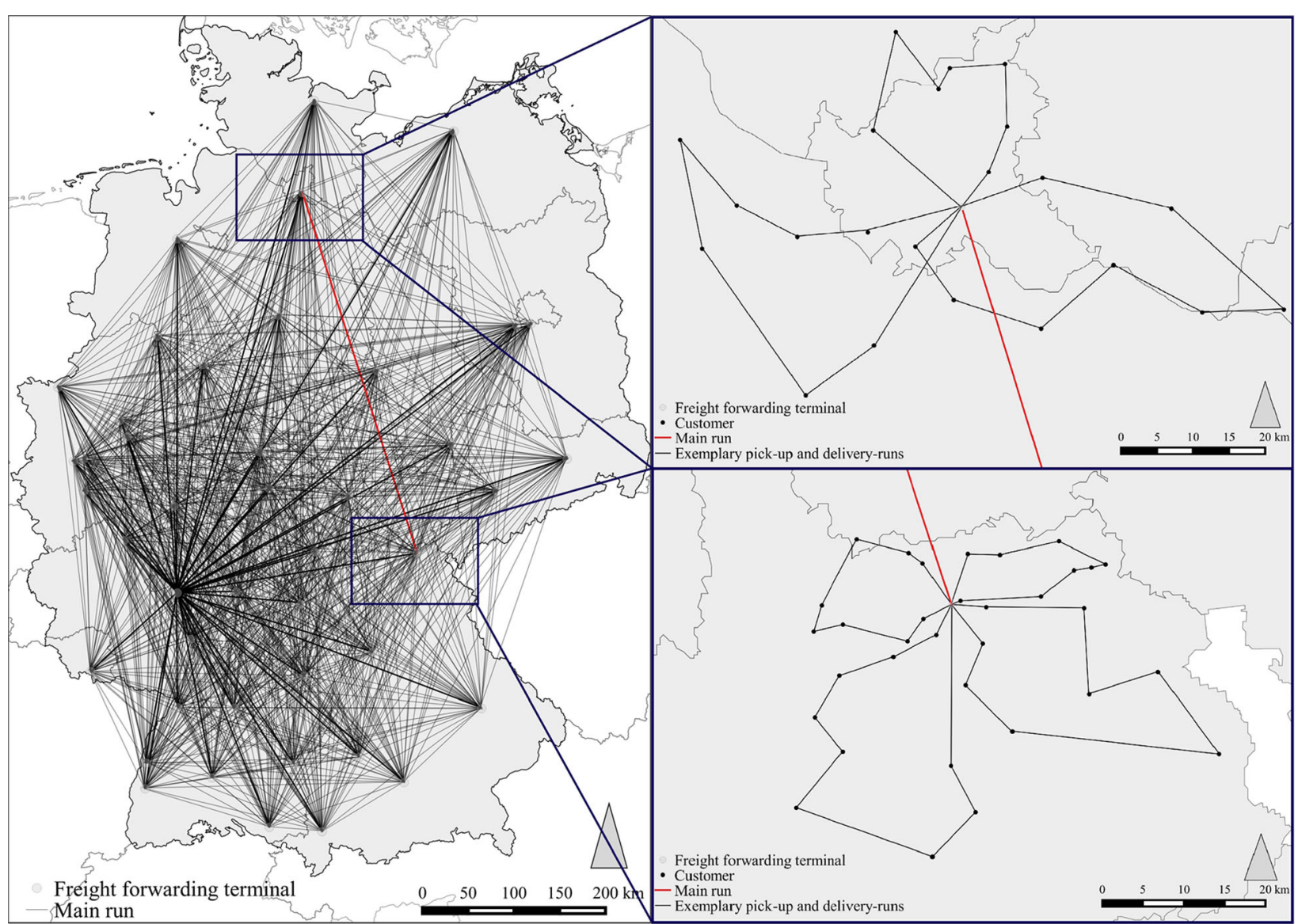

Fig. 1 Connections of transport logistics hubs of freight forwarding networks in main runs and local runs

flow of commodities between the zones is calculated. There are different methods (e.g., gravity approaches) which are suitable for this procedure. The output is an origin-destination matrix that describes the sources and sinks of the commodity flows. Mode choice and/or choice of means of transport (depending on the model) are determined in step three (mode choice). Once the flows of goods are converted into vehicles, the demand is assigned to the supply network in the fourth and final step (traffic assignment) [1, 14].

We will recover these steps in most of the models reviewed in this article. Furthermore, the short explanation of the model characteristics above provides a better placement for the upcoming argumentation of the different models.
Table 1 Differentiation of transport and distribution logistics hubs (based on [44])

\begin{tabular}{|c|c|c|}
\hline Characteristics & Distribution logistics hub & Transport logistics hub \\
\hline number of sources & few & many \\
\hline number of sinks & many & many \\
\hline main function & $\begin{array}{l}\text { storage, consolidation, distribution, } \\
\text { packaging, value adding services }\end{array}$ & transhipment, certain buffer function \\
\hline user & one or certain number of users & many different and changing customers \\
\hline operator & $\begin{array}{l}\text { own account or logistics service } \\
\text { provider (3PL) }\end{array}$ & logistics service provider, forwarding agency \\
\hline destination & sink is uncertain ${ }^{a}$ & sink is certain ${ }^{b}$ \\
\hline examples & $\begin{array}{l}\text { distribution and/or consolidation } \\
\text { centres, warehouses }\end{array}$ & $\begin{array}{l}\text { intermodal freight terminals, locations } \\
\text { of forwarding companies, seaports, } \\
\text { inland ports, airports }\end{array}$ \\
\hline
\end{tabular}

\footnotetext{
${ }^{a}$ At the moment the goods arrive at the distribution logistics hub the final destination is not defined. The final destination will be defined during the picking process only

${ }^{\mathrm{b}}$ Each shipment is labelled with an explicit destination before it reaches the transport logistics hub
} 
Table 2 Model properties (based on $[14,15,30])$

\begin{tabular}{lllll}
\hline Resolution & Scale of analysis & Depth of aggregation & Measure variable & Method of modelling \\
\hline international & macroscopic & aggregated & trip-based models & econometric models \\
national & mesoscopic & disaggregated & flow based models & spatial equilibrium \\
regional & microscopic & & hybrid models & network-based models \\
urban & & & \\
sub-urban & & & \\
\hline
\end{tabular}

\section{Consideration of logistics and logistics hubs in freight transport demand models}

This chapter will show that logistical elements found inadequate or no consideration in most national models until a few years ago. This hampered the accurate mapping of freight transport and logistics as an import influencing factor. An overview of developments in freight transport modelling concerning the integration of logistics will be given in the section below. Thus, the following introduction provides the general frame for the subsequent presentation of different models that consider logistics and transport logistics hubs in particular.

Early attempts towards integrating logistics aspects into models can be found in the field of disaggregated modelling dealing simultaneously with mode choice and logistics choices. In Chiang et al. [7] mode choice decisions are embedded in a larger inventory-theoretic and logistic framework. Winston [50] stated in his review that models in application were lacking logistics aspects since the time his article was published. The paper from Bergman [5], presented at the International Meeting on Freight, Logistics and Information Technology, can be recognized as the starting point of integrating transport logistics into modelling. He proposes a more detailed spatial representation of logistics processes in freight logistics models. Introducing elements of logistics decision-making in freight models took off in the Netherlands in the early 1990s. Furthermore, it has taken years before similar approaches started to be adopted elsewhere [39].

Broadly speaking, there are different models taking logistics into account. These models are currently operated in different countries and, to some extent, across borders. Although transport demand modelling concerning logistical matters has developed enormously in recent years, there are currently only a few models in use that incorporate logistical aspects concretely [27]. Some examples can be found in the British EUNET, the Dutch SMILE or in the Spatial Logistics Appended Module (SLAM) realized in the European model SCENES. The national transport model system implemented in Sweden and Norway (SAMGODS and NEMO) represent prime examples in this domain [43].
Even though there are different articles dealing excellently with integrating logistics into freight transport modelling (see. e.g., $[14,15])$ these reviews do not focus on the integration of transport logistics hubs in particular. Almost all papers review international models in a more general way and address the integration of logistics in general. Differing to that, the following part focusses specifically on the integration of transport logistics hubs (see chapter 2) in models in application. Below we will present an overview of models in operation that consider logistics aspects and hubs. We chose to present the following models because until the end of the research those models were the only existing models in application that integrate logistics and logistics hubs to some extent. Therefore, they represent the most interesting models in use in respect to the topic of this paper. Due to the fact that the reviewed models differ in their characteristic (e.g., scale, depth of aggregation, resolution, etc.), the basic functionality as well as the integration of logistics will be explained, at first. Subsequently, the analysis will focus on the integration of transport logistics hubs.

The model applied to the area of Sweden, named SAMGODS, is a model of national resolution and macroscopic scale of analysis. From a certain point of view it can be seen as a mixed model (see next section) when referring to its depth of aggregation. The model is based on several submodels that take into account developments of economy, trade as well as foreign trade etc. from which it derives traffic generation. The model considers 35 commodity groups and offers 86 predefined transport chains (with 34 possible means of transport) for transportation processes via a multimodal network. Decisions on shipment size, suitable routes and means of transportation are achieved by a logistics module [11, 39, 47, 49].

The logistics module consists of three steps and follows the ADA structure (aggregated-disaggregated-aggregated). Flows of goods between places of production and consumption are firstly provided on the aggregated level. In order to assign them to individual firms they are disaggregated. Consequently, firms' logistics decisions (shipment size, utilization of collection and distribution centres, etc.) can be simulated in this 
disaggregated part of the model. To allocate the ODflows to routes, the data are finally aggregated again [10].

Selecting one of the predefined transport chains, the logistics module sets modes of transport for each section and determines whether transport is accomplished directly or via the utilization of logistics hubs. Transport logistics hubs are also included in the model - defined as locations were goods are transhipped and possibly stored [11]. The logistics module consists of subroutines that develop decisions gradually. Therefore, available transport chains, including optimal transfer points between transport sections, are generated initially in a first subroutine (BUILD CHAIN). This one is followed by a second, which selects transport chains with regard to minimising total logistics costs (CHAIN CHOICE) (see Fig. 2).

These costs include costs resulting from different processes during the transport: costs for loading/unloading processes at the sender/receiver, costs for the transport itself, as well as costs from inventory management, for instance, at warehouses. Due to the fact that the model also includes transhipment processes, linking different legs of the transport chain, the corresponding costs incurred by using transport logistics hubs are also considered (transport logistics hubs like truck terminals, ports, intermodal terminals and airports). Included costs then vary per ton and vehicle type.

Existing information regarding terminal properties (e.g., access to different modes; spatial situation; feasibility of handling different types of goods etc.) is considered as well. Due to economies of scale, for instance, or differences in technologies operating at hubs, the derived costs vary at these nodal points. Therefore, the model distinguishes between different classes of terminals, which are characterized by a technology factor between zero and one. It is based on the assumption that, for example, ports which handle more goods use more advanced technologies $[10,11,13]$.

Beside a general integration of hubs, the differentiation of diverse types of transport logistics hubs represents a further step in considering and distinguishing hubs in demand modelling - also with regard to node-specific characteristics within a category $[11,13]$.

NEMO (Network Model for Freight Transport) is a national model applied to the area of Norway. Due to its evolution (parallel with SAMGODS), NEMO considers logistics hubs similarly to SAMGODS. Thus, the model represents an extension of the Swedish one to the spatial area of Norway and, therefore, will not be examined separately.

The Dutch model SMILE (Strategic Model for Integrated Logistics Evaluation), which predicts traffic flows at the national level, was one of the first models to consider logistical aspects.

SMILE simulates transport flows by taking economic developments into account and linking the economy, logistics and transportation. It was the first model especially developed to include distribution centres into the routing processes of commodity flows [39]. Land use (via production), trade (via sales, sourcing), logistics (via inventory) and transport are coupled across four stages [40].

The impact of logistics hubs, which is represented by distribution centres in this case, becomes noticeable by considering hub characteristics, and the attributes of goods and their requirements in terms of inventory, handling and transportation. With respect to this, 542 different types of products are clustered into 50 logistics families. The clustering process is based on certain characteristics of the product (e.g., value of goods, packing density, perishability, delivery time, shipment size etc.). The characteristics of these logistics families impact the potential and capability to handle certain types of goods. Therefore, hubs influence distribution chains and transport flows, and provide a spatial redistribution of the flows of goods through handling and stock rates, packaging density and volume to weight related to hub characteristics (see Fig. 3) [40].

The mapping of distribution centres with appropriate opportunities of consolidation and the resulting transport flows

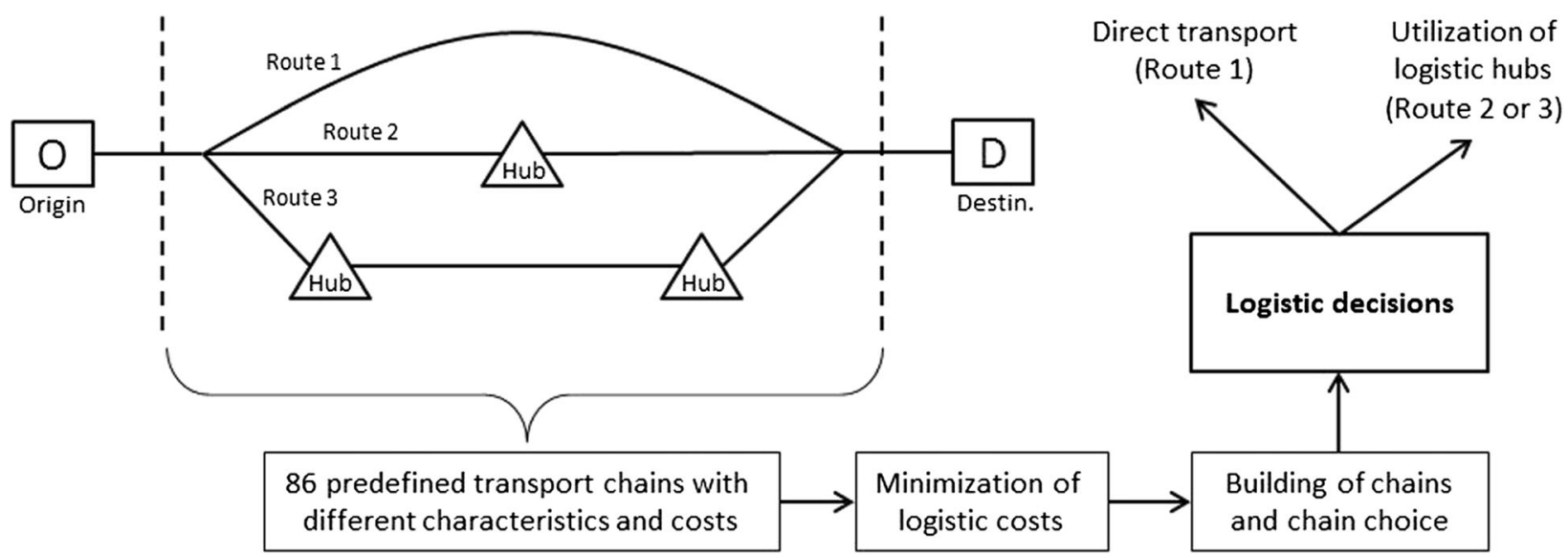

Fig. 2 Integration of logistics hubs in SAMGODS (based on [12, 13]) 


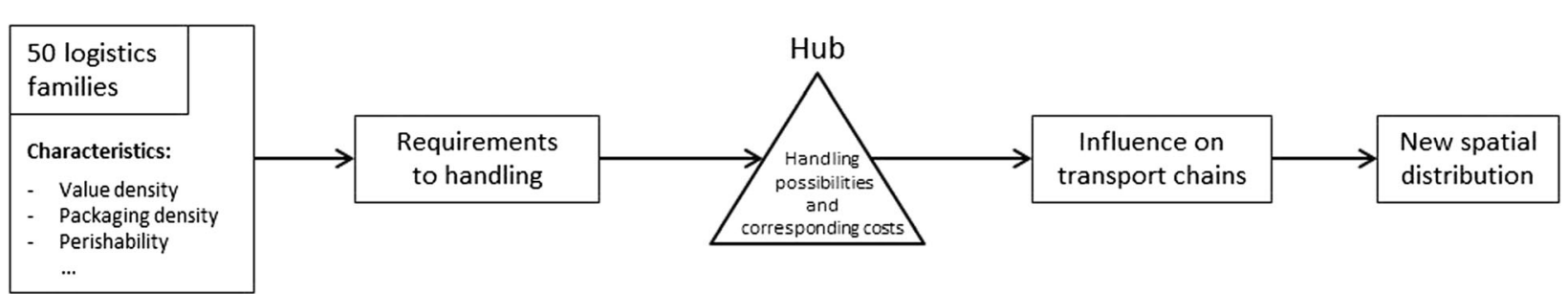

Fig. 3 Hubs in SMILE (based on [40])

based on characteristics of goods and hubs is one way to include hubs in transport demand modelling. Similar to other models, trade and transport relations are linked with inventory and storage services in SMILE. However, transport logistics hubs are not considered in particular.

The Spatial Logistic Appended Module (SLAM) is integrated in the European model SCENES (trans-boundary macroscopic model for the EU). During the development, basic ideas and experiences from the Dutch model SMILE were consulted. SLAM is designed to evaluate the effects of changes in logistics and in the transport system across Europe. Therefore, a major application is the detection and location of distribution centres in Europe. Accordingly, SLAM ought to give a more accurate picture of transport flows involving logistical matters. The model considers changes in distribution structures (e.g., number and location of utilized intermediate warehouses for distribution) and incorporates them into the distribution flows [11, 16, 43].

SLAM receives production and consumption flows (e.g., from SCENES) and produces origin-destination-matrices (OD-matrices) that integrate alternative distribution chains. In this context a distribution chain is defined as the combination of distribution centres and transportation relations for trade flows between producer and consumer region. In this manner, a main function of the model is the consideration of alternative distribution chains (production - distribution centre - consumption) (see Fig. 4) [16, 39].

In order to determine alternative distribution chains, located hubs are listed in accordance to characteristics of products, markets and transport services. A location score module then calculates a score for each region related to its attraction as a possible location for distribution centres (based on economic activity, centrality and accessibility to infrastructure etc.). Afterwards, a chaining module selects the most attractive regions for distribution centres and constructs logistics chains via these centres. Furthermore, logistics costs are calculated for each single chain composed of transportation, inventory and other logistics costs. The construction of transport chains thus follows the approach of minimizing total costs $[9,26]$.

Returning to the model structure, it can be stated that SLAM achieves a more accurate picture of transport flows by integrating distribution logistics hubs in the transportation system. Since the hubs considered represent distribution centres, the picture is not adequate regarding transport logistics hubs. In addition, SLAM does not go into detail concerning networking because flows act strictly cost-rationally and, therefore, take the most cost-effective way through the abstract distribution-consumption-net.

EUNET is a regional model developed in the UK. It covers the goods transport within central Great Britain (Trans Pennine Corridor) as well as imports and exports from and into the region. Similar to SCENES, whose principles served as orientation in the development process, EUNET provides a link between regional economics and logistics. The aim of the model is to predict freight transport demand as a function of economic transactions and freight logistics $[11,14,43]$.

Analogously to other models, EUNET contains a logistics module, which serves as a link between PC-matrices and ODmatrices [39]. Since logistics hubs (consolidation centres, national/regional distribution centres, major ports, local depots etc.) - here mostly defined as distribution logistics hubs or special generators - are included in the formation of ODmatrices, they play a crucial role. The distribution of commodity flows through logistics hubs is, comparable to other models, based on the properties of each hub (e.g., warehouse floor space data). Thus, logistics steps are explicitly considered by relating handling factors of products and characteristics of logistics hubs [22, 41].

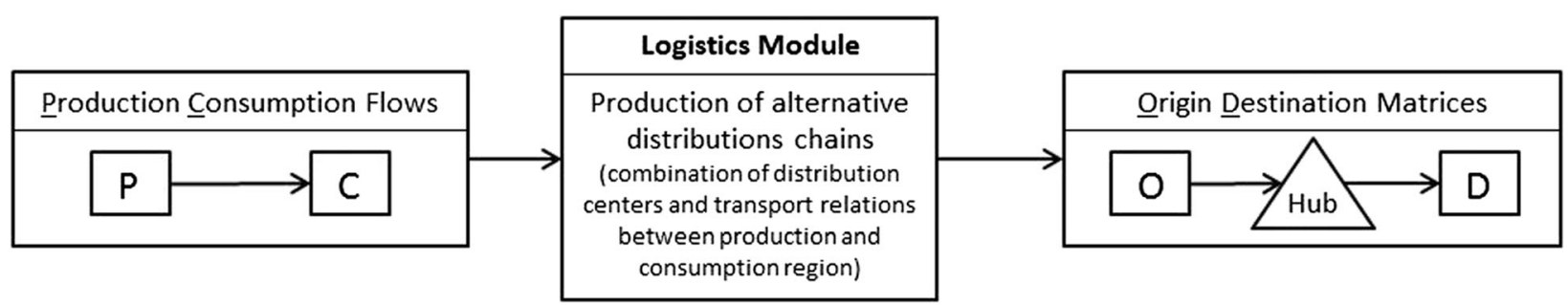

Fig. 4 Hubs in SLAM (based on [16, 43]) 
In this way, multiple distribution channels arise via a plurality of possible hubs (see Fig. 5) [22]. The consideration of distribution logistics hubs is achieved by the inclusion of hub characteristics and goods attributes. Nevertheless, transport logistics hubs, however, lack consideration here.

The Los Angeles Freight Forecasting Model - LAMTA is a multimodal transport demand model. Although the model for the Los Angeles Metropolitan Area (LAMA) mainly focusses on road freight transport (trucking), it also includes a multimodal framework to support freight transportation decisions and, hence, logistics hubs [3, 17].

Besides the sub-components for trip generation, trip distribution, and mode choice, LAMTA integrates a separate module explicitly aimed at modelling logistics hubs which are not included, for instance as special generators. The Transport Logistics Node Model (TLN) incorporates warehouses, distribution centres and intermodal terminals into its modelling. However, this affects long-distance freight transport - precisely defined as flows between zones situated inside the LAMA and external regions (outside LAMA). Commodity flows occurring entirely within the study area are not modelled by the TLN. Therefore, transport logistics hubs within the study area are defined as hubs where chains for long-haul transportation are formed (see Fig. 6). Some examples for these transport logistics hubs are intermodal freight yards, truck terminals and other loading facilities $[3,17]$.

The TLN module is based on two elements. First, characteristics of the logistics hubs are described by the TLN module. After that, OD-matrices are fed into the TLN in order to generate separate matrices for each combination of transport mode and commodity. For that purpose, the commodity flows are split into two segments. Long-haul traffic carried out by truck, rail or ship is distinguished for each direction (inbound/outbound). Thus, the percentage of shipments passing each hub is calculated for each product group and direction. In addition, a further allocation to short-distance transport, which is performed by trucks only, is carried out as well [3]. The final output of the TLN-module is four matrices per transport mode and product group (direct short-distance transport without TLN; direct long distance transport without TNL; long distance transport from/to TLN, short-distance transport from/to TLN).
Finally, transport logistics hubs are only considered in LAMTA when commodity flows cross the LAMA border.

Due to the appointment of the Chicago Metropolitan Agency for Planning (CMAP), a powerful and innovative prototype of meso-scale freight model was developed for Greater Chicago.

The model consists of a macro-scale model that generates commodity flow data on macroscopic level using economic modelling tools. Its' output serves as input for the meso-scale model that breaks down the high-level commodity flows on shipments between individual companies by agent-based analysis and disaggregated choice modelling. Within this, the demand in the Chicago region is explained by several steps (generation of firms for production and consumption; creation of individual relations between firms; disaggregation of macroscopic flows of goods to annual shipments between buyer and seller; choice of transport and logistics paths). By means of the output of the meso-scale model, a dynamic multi-modal route assignment is made in a last step and detailed trips are generated in a micro-scale environment $[45,46]$.

In addition to data from the macro scale model, there is also input data coming from a network model. As a result of this, logistics facilities and hubs (intermodal terminals, rail terminals, container and loading terminals, distribution centres as well as other freight hubs, airports and water ports and also large firms) are included in the evaluation of logistics and transportation decisions $[31,45]$.

Several distribution channels via hubs were identified using data collected by a national survey (FAME project). Shipments that require, for example, intermodal loading facilities, warehouses or distribution centres are assigned to corresponding hubs. Costs that emerge at these hubs (e.g., intermediate handling, inventory, deterioration, damage and ordering or stock out costs) - based on hub characteristics - influence the total costs of the different shipment types [33]. Following the steps mentioned above, transport decisions are ultimately based on evaluation of total transport and logistics costs relating to available paths [31].

The approach of the model for the CMAP follows mainly the research of de Jong and Ben-Akiva and their comprehensive accounting of transport and logistics costs and is,

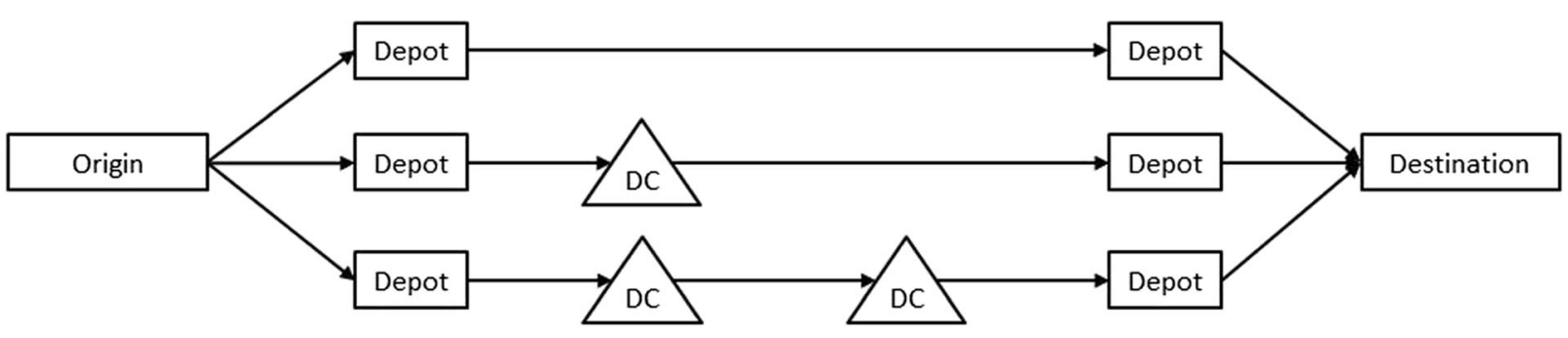

DC - Distribution Center

Fig. 5 Hubs in EUNET2.0 (modified illustration from [22]) 


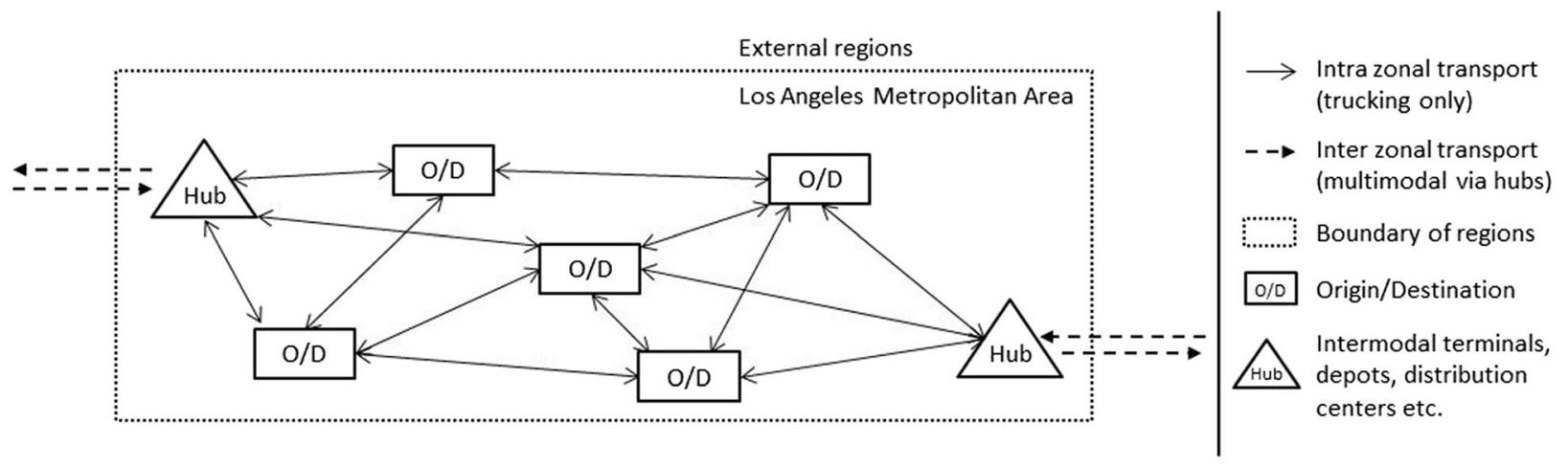

Fig. 6 Hubs in LAMTA (based on [3])

therefore, similar to the aggregated-disaggregated-aggregated (ADA) approach used in SAMGODS and NEMO.

The concept for the freight transport model FAME (Freight Activity Micro simulation Estimator), developed at the University of Illinois (Chicago), is a fairly new conceptual modelling framework. It was designed for behavioural freight transportation modelling and considers logistical elements in detail. Therefore, it focusses iteratively on the benefit of different types of intermediate handling facilities, mode choice, and shipment size [36].

Initially, individual decision-makers with their specific characteristics and geographical distribution are introduced in the firm-type generation. Trade relations between firmtypes are determined in the following module (supplier selection). The subsequent determination of shipment size and frequency is based on observed shipment size distributions. A probit model is used for behavioural mode choice before the commodity flows are finally assigned to the network [34].

Logistics aspects and hubs are taken into account via considering logistics transport chains. Thus, the number of stops and mode choice are determined for each of the corresponding shipments and chains. In addition, logistics hubs are defined and optimal shipment sizes are determined for each transport chain passing related hubs. There are different combinations and transport chains to connect suppliers and buyers. Apart from direct transportation, transport chains may pass intermodal terminals, distribution and consolidation centres with various combinations of these within the chain $[34,36]$.

Characteristics of commodities (e.g., shipment size) and costs are the crucial variables that influence the utilization of logistics hubs in the model.

Only few agent-based or rather actor-based models have been developed in order to incorporate behavioural elements of logistics actors [35]. The actor-based approach to commodity transport modelling developed by Liedtke (InterLog) is such an approach. The model involves both commodity and vehicle-related aspects and, therefore, combines two in modelling mostly parallel existing approaches.

The agent-based approach (integrates logistical elements into modelling road freight transport by considering decisions taken by individual actors. Senders and receivers are classified according to produced and consumed commodities in the model. They are equipped with appropriate behavioural parameters. Logistical strategies and decisions are included in transport-related decisions by emerging total logistical costs. These costs include ordering and communication costs, inventory costs, costs for loading and unloading as well as general transport costs. Furthermore, total logistics costs are influenced by goods' characteristics and business relationships that are crucial to distribution and transport deals between actors.

Choices of agents (firms, freight forwarders) are modelled in a market interaction model in order to examine their interactions within the transport market and their ambitions to maximize their profits by minimizing total logistics costs. Minimizing cost also involves adjusting delivery frequencies and the contracting of suitable transport companies. In this way, the InterLog model represents one of the first models to integrate aspects of behaviour in terms of microscopic modelling. [26, 27].

Although the model illuminates transport behaviour of the transport company and, thus, related logistical aspects, the utilization of transport logistics hubs is, however, not regarded. There is no explicit consideration of this aspect because the model focuses primarily on the decisive logistical factors of shipment size and existing contracts between senders/receivers and transport operators. Complex logistical reaction patterns between actors are examined in this way. However, transport logistics hubs are not linked with actors and, therefore, not represented in the model.

GoodTrip - the model applied to Groningen (Netherlands) is an urban freight transport model. It builds logistics chains by linking the activities of consumers, supermarkets, hypermarkets, distribution centres and manufacturers and is fundamentally based on consumer demand [39].

The four component model (components: spatial organization of activities; freight flows; transportation; infrastructure) calculates the volume of goods per commodity group for each spatially defined zone [6]. Thus, the attraction of goods between consumers and producers is determined. Within this 
determination the flows of goods are influenced by the spatial distribution of activities and the market share of each activity group (consumers). Afterwards a classification of commodity groups is carried out and an OD-matrix is created. In a final step, vehicle trips are generated and assigned to a network [ 35 , $39,43]$.

Although the model considers logistics aspects, transport logistics hubs are not covered explicitly, for example as loading facilities or similar. Indeed concepts of urban distribution centres can be considered in different scenarios. Scenarios for urban logistic distribution centres are one example here (see Fig. 7) [6].

The impact of logistics hubs in general and transport logistics hubs in particular on transportation is, however, disregarded within the study area, from a large-scale perspective.

The urban/regional model developed by the IVU Traffic Technologies AG called WIVER found its application in several cities and their surrounding area, including greater Hamburg and Berlin. It offers the ability to consider transport effects of logistics hubs [38].

The model mainly focuses on road transport and calculates freight transport demand in four steps. Thus, originating traffic is identified and derived from structural data related to traffic areas (e.g., economic sectors, number of active driving employees of companies). The originating traffic is then determined by the average number of trips and destination. In a second step, the terminating traffic potentials are calculated based on the distribution of industries and recipient structure of these industries. These characteristics are used to weight originating trips to destination. Subsequently, origins and destinations are linked by their volume and potential as well as taking into account distances, for instance. In a final step, tours are generated and assigned to a network model [21].

Due to the incorporation of the enterprises' mobile employees (conductors) into the model parameters, logistics hubs are considered in a special way. However, hubs are integrated in trip generation, only, so that they are not included in tour construction as intermediate stops within transport chains, for instance.
Table 3 provides a summary of all models presented here and gives an overview of the model specifications and the integration of different types of logistics hubs.

Further details of models can also be found in de Jong et al. [15], which provide a more general overview over some models (e.g., SMILE, SAMGODS etc.). In contrast to de Jong et al. [15], Table 3 focusses on the integration of logistics hubs and transport logistics hubs in particular. We can summarize that most models integrate distribution logistics hubs (DLH) but, however, transport logistics hubs (TLH) are integrated in few models, only. The combination of Table 1,2 and 3 gives an insight in how transport logistics hubs are integrated in freight transport models in application.

In order to summarize the insights into the different models it can be stated that there are different ways to integrate transport logistics hubs in modelling.

A rather basic method is the integration of hubs as sources and sinks in models. Thus, logistics hubs are considered in a simple way as so-called special generators or singular traffic generators whose transport volume is supplied/defined externally.

The integration of transport logistics hubs via logistics modules, which select between several predefined transport chains, is a more sophisticated method. A decisive influence on the consideration of hubs within logistics modules is the properties of shipments (e.g., commodity, shipment size). Due to the characteristics of hubs there are often limits in handling certain shipments. If hubs are not suitable to handle a certain shipments, the likelihood of transportation via these hubs will be reduced. Different transport chains, processing only via certain hubs, are the result of that consideration. In this manner, the characteristics of hubs in combination with the characteristics of shipments determine the utilization and impact of hubs or transport demand respectively. Another aspect of integrating logistics hubs into modelling is the inclusion of further hub characteristics that excess the characteristics mentioned above (capability of handling certain shipments). The integration of information about differences in technologies used at hubs, for instance, can turn out to be very helpful if

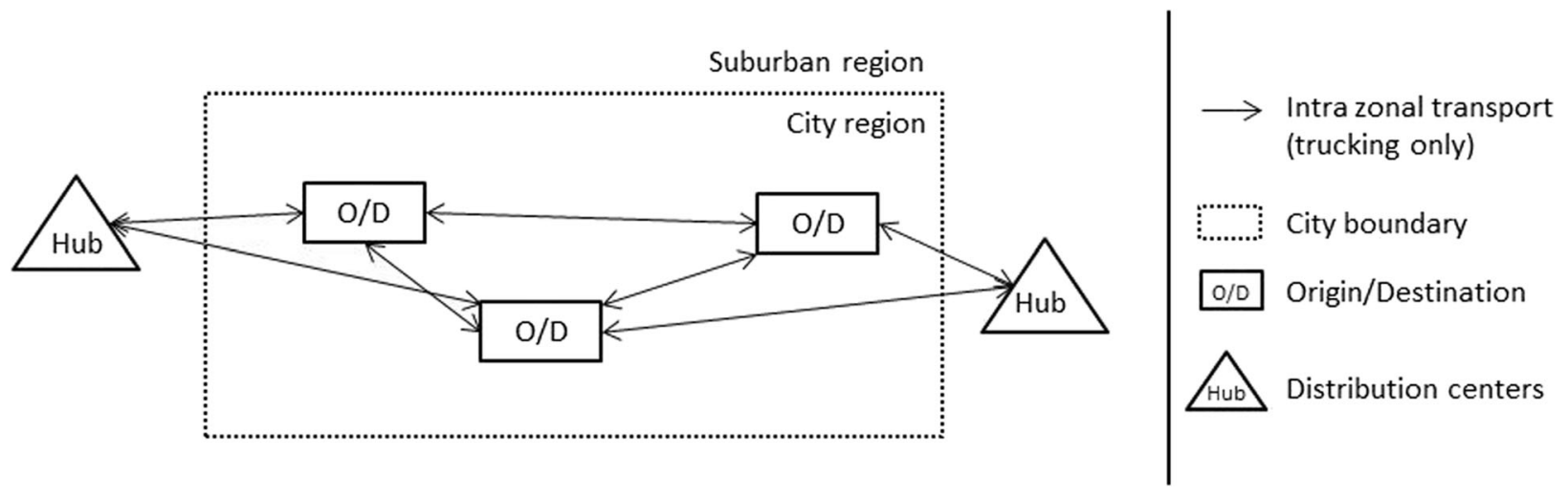

Fig. 7 Hubs in GoodTrip (based on [6, 39]) 
Table 3 Model highlights

\begin{tabular}{|c|c|c|c|c|}
\hline Model & Resolution & Scale of analysis & Depth of aggregation & Type of hubs considered \\
\hline SAMGODS / NEMO & national & macro & aggr./disaggr. & DLH, TLH \\
\hline SMILE & national & macro & aggr. & DLH \\
\hline SLAM & regional / international & macro & aggr. & DLH \\
\hline EUNET & regional / national & macro & aggr. & DLH \\
\hline LAMTA & urban/regional & macro & aggr. & DLH, TLH \\
\hline CMAP & urban/regional & macro / meso & aggr./disaggr. & DLH, TLH \\
\hline FAME & national & micro & disaggr. & DLH, TLH \\
\hline InterLog & national / regional & micro & disaggr. & DLH \\
\hline GoodTrip & urban & micro & disaggr. & DLH (TLH) \\
\hline WIVER & urban/regional & micro & disaggr. & DLH, TLH \\
\hline
\end{tabular}

$D L H$ distribution logistics hubs, $T L H$ transport logistics hubs

used technologies vary significantly. This way offers the possibility to a more nuanced consideration of hubs if they differ regarding their characteristics.

Considering the gained information, we will discuss the results and its broader meaning as well as consequences for transport demand modelling in the next section.

\section{Discussion}

The review of freight transport demand models revealed several things: first of all there are numerous models which are used to forecast transport demand or rather to assess policy measures (although only few models were presented here). The review also shows that logistical aspects found more and more consideration in freight transport demand modelling over the years. Thus, new possibilities opened to integrate logistics into modelling and to achieve greater realism. However, the review also showed that, until the date of analysis, only few models consider logistics in general and only to a certain degree - namely the models presented in chapter four. This fact also points out that there is a huge discrepancy between models in application. A small number of models considering logistics aspects face a huge number of models excluding logistics. This is caused by different reasons such as the models' intension or the year of development, of course. Furthermore, the integration of logistics aspects also differs within the "pool" of models that consider logistic depending on model specification (e.g., the spatial scope or resolution).

Secondly, the analysis of the models presented in this article revealed that integrating logistics aspects does not always include the integration of logistics hubs - regardless what type of hub. The conclusion that a model integrates logistics does not always hit the mark in this manner, because logistics comprise several aspects and components - such as the utilization of transport logistics hubs. A more detailed view is appropriate here, so that we had to expand the horizon on the integration of logistics in modelling by adding the specific focus of the integration of transport logistics hubs. This expansion is of major importance because transport logistics hubs are highly relevant in transport and logistics processes (see chapter 2) - so they are for adequate freight transport modelling in order to assess policy measures realistic.

The review revealed that there are only few models, which consider logistics hubs in general. Although logistics hubs are currently taken into account in most of the reviewed models, it has to be kept in mind that the considered hubs are mostly distribution logistics hubs, which can be derived from the definition of hubs through their function (see chapter 2). Refocussing on the objective of our article we have to state that transport logistics hubs are included in much less cases and detail than has so far been the case with distribution logistics hubs (see chapter 4).

Regarding the models that integrate transport logistics hubs there are also differences in the types of transport logistics hubs that are considered. There are a) noticeable differences between the models and the considered hubs. Some transport logistics hubs occur more often in models (e.g., terminals for combined transport, sea ports or rail ports) but there are, however, also a lot of hub types that are not considered (e.g., transhipment hubs of freight forwarders) - even not by the models that can be considered as the most up-to-date ones. Furthermore, there is b) only one approach (SAMGODS/ NEMO) that integrates all relevant types of hubs that are important in freight transport.

These overall results are astonishing because transport logistics hubs - see, for instance, transhipment facilities of freight forwarders - bear a significant meaning in freight transport (see chapter 2). The absence of relevant hubs leads to less detailed modelling of, for example, commodity flows and, thus, transport processes. Less detail leads to less explanatory power and, therefore, to less sensitivity of models. This directly impacts the ability of models to estimate transport 
forecasts more precisely or to deal with different policy measures and, thus, to assess their effects on transport accurately.

We encourage closing this gap because the integration of relevant transport logistics hubs will improve the assessment of policy measures regarding transport logistics. Due to the importance of transport logistics hubs the, at least, most relevant ones should be integrated in the models. Terminals of combined transport, rail and sea ports but also ports of inland waterways and especially transhipments facilities of freight forwarders should be integrated - also to credit their empirical relevance within transport processes.

However, hub-specific data are needed to integrate transport logistics hubs and extend existing models or build new ones. It seems to be a very obvious and evident reason that data availability limits the integration of hubs, in this manner. Thus, models and their capability to consider transport logistics hubs vary as much as the available data. National statistic agencies, for example, mostly publish aggregate data which do not offer comprehensive information, especially on the level of individual shipments and their description of origin and destination, value, weight, mode of transportation, as well as spatial information on transport logistics hubs. We are aware of the fact that there are exceptions but, however, the majority of public accessible data are aggregate in most cases. If there are detailed and high quality data available, it is usually for specific areas or economic sectors, which hampers the transferability of specified models. If there are no comprehensive available data, the used aggregate data do usually limit detailed modelling and do only provide the basis for an aggregate and more general overview. The absence of detailed data is fatal in general but also particularly when focussing on transport logistics hubs. The availability of comprehensive and high quality data is a major challenge.

A major question arising from the analysis here is, therefore, which data could help to achieve an adequate integration of transport logistics hubs into transport demand modelling? There are supplementary requirements to data in order to achieve an adequate integration of transport hubs. Such data should contain information about a) hub characteristics (e.g., total area, handling capacity, branches of clients) but also regarding b) the transport process itself (e.g., means of transport, transport objects, transport volume). This supplementary information (see Table 4) would enable an improved integration of transport logistics hubs.

Using new data containing the attributes mentioned above will help to derive key parameters in order to discover correlations and dependencies between certain hub characteristics and the specific role of hubs in the transport process. In this manner, the influence of the parameters on freight generation of transport logistics hubs and their role in the freight transport network could be illuminated. This would also help to develop new approaches to integrate transport logistics hubs adequately in freight transport demand modelling, which could then be
Table 4 Required data for improved integration of transport logistics hubs

Important attributes that characterise transport logistics hubs

$\begin{array}{ll}\text { Basic data of hubs (e.g., area) } & \text { Means of transportation } \\ \text { Total area } & \text { Transport objects } \\ \text { Handling area } & \text { Infrastructural connection } \\ \text { Handling capacity } & \text { Branches of clients } \\ \text { Number of trips } & \text { Loading units and handling facilities } \\ \text { Number of vehicles } & \text { Transport volume } \\ \text { Transport distance } & \text { Type of business } \\ \text { Network structure } & \text { Empty trips and capacity utilization }\end{array}$

achieved in far more detail by models. The detailed integration of transport logistics hubs would lead to greater realism of models, which would enable policy decision makers to assess policy measures in a more accurate way.

\section{Conclusion}

This review has investigated the integration of transport logistics hubs in freight transport demand models. The article revealed whether and how transport logistics hubs are currently considered in transport demand models. It showed that the growing relevance of logistics in freight transport has been considered in demand modelling in last decades by integrating logistic aspects in some models to a greater extent. This development was important because models are relevant tools in order to forecast transport demand and to support decisionmakers through the assessment of transport policy measures. However, the analysis showed that although freight transport demand models have experienced remarkable improvements in recent decades, important logistical aspects have so far been taken insufficiently into account.

Within freight transport processes, transport logistics hubs gained growing empirical significance in the recent past. This implies a major relevance to consider them in demand modelling, too. Nevertheless, the review revealed that the consideration of transport logistics hubs in freight transport demand modelling varies significantly. The majority of the existing freight models $(\approx 100)$ do not integrate transport logistics hubs. Models in application focus on distribution logistics hubs in many cases but only few integrate transport logistics hubs to some extent.

The integration of transport logistics hubs then differs in many ways. This applies especially for the different types of transport logistics hubs. Not all types are considered by all models. Furthermore, consideration does not only differ quantitatively (number and types of hubs) but also qualitatively (detail of hub integration). In a nutshell: there is only one 
model that integrates transport logistics hubs in an adequate manner.

It becomes clear that there are certain restrictions which hamper hub integration. The potential of many models is limited by reason of data availability. In order to integrate hubs more adequately detailed data are needed. The lack of adequate and detailed data remains a major challenge that is, frankly, not new to the freight modelling community.

Therefore, a major challenge is also to launch additional surveys in order to supplement existing data. Discovering correlations as well as deriving key parameters and integrating them into modelling will help to determine the effect of transport logistics hubs on transport demand more accurately. This will enable scientist as well as practitioners to make more reliable statements or prognoses regarding the assessment of measures relating the transport system.

Sketching options for future research endeavours seems to be easy in that case. The lack of hub-specific data reveals that surveying supplementary data is unavoidable. However, closing the data gap by collecting proper data to improve the integration of transport logistics hubs in modelling will be a major challenge. Nevertheless, this step seems to be unavoidable to improve existing models and achieve greater realism, which is fundamental regarding the assessment of policy measures.

In order to tackle these challenges and achieve this greater realism transport logistics hubs should be spotlighted in freight transport demand modelling but also in empiricism.

Acknowledgments This compilation and analysis was integrated in the project 'Integration of logistics hubs and their specific transport volume in freight transport demand modelling'. The authors gratefully acknowledge the co-funding of this work enabled by the German Research Foundation (DFG) under contract CL 318/12-1 and LE 1137/4-1.

Open Access This article is distributed under the terms of the Creative Commons Attribution 4.0 International License (http:// creativecommons.org/licenses/by/4.0/), which permits unrestricted use, distribution, and reproduction in any medium, provided you give appropriate credit to the original author(s) and the source, provide a link to the Creative Commons license, and indicate if changes were made.

\section{References}

1. Arndt WH (2005) Modelle für den Wirtschaftsverkehr - ein Überblick. Technical University of Berlin. Institute for Land and Sea Transport Systems

2. Baumgarten H, Walter S (2001) Trends und Strategien in der Logistik 2000+: eine Untersuchung der Logistik in Industrie, Handel, Logistik-Dienstleistung und anderen Dienstleistungsunternehmen. Technical University of Berlin. Department of Economy and Management

3. Beagan D, Fischer M, Kuppam A (2007) Quick response freight manual II. Technical Report. U.S. Department of Transportation. Federal Highway Administration
4. Ben-Akiva M, Meersman H, Van de Voorde E (2013) Recent developments in freight transport modelling. . In: Moshe Ben-Akiva, Hilde Meersman, Eddy Van de Voorde: Freight Transport Modelling

5. Bergman T (1987) New generations of freight models: more logistically oriented models, need and possibilities. International Meeting on Freight. Logistics and Information Technology, The Hague

6. Boerkamps J, van Binsbergen A (1999) GoodTrip - A New Approach for Modelling and Evaluation of Urban Goods Distribution. Technical report, Delft University of Technology Faculty of Civil Engineering and Geo Sciences, Transportation Planning and Traffic Engineering Section and The Netherlands Research School for Transport, Infrastructure and Logistics (TRAIL)

7. Chiang Y, Roberts PO, Ben-Akiva M (1981) Development of a policy sensitive model for forecasting freight demand. Final Report, Centre for Transport Studies, Report 81-1, MIT, Cambridge, Massachusetts

8. Clausen U, Iddink U, Neumann L (2008) Approaches for modelling commercial freight traffic regarding logistics aspects. Proceedings of the 3rd International Symposium on Transport Simulation. Surfers Paradise, Australia

9. Combes F, Leurent F (2007) Advances in freight transport demand modelling: An assessment with research perspectives. European Transport Conference

10. de Jong G (2005) The development of a logistics module in the Norwegian and Swedish National Freight Model Systems. Technical report. Rand Europe and Sitma. Report for the Samgods group and the Working group for transport analysis in the Norwegian national transport plan. Netherlands

11. de Jong G, Ben-Akiva M (2007) A micro-simulation model of shipment size and transport chain choice. Transp Res B Methodol 41:950-965

12. de Jong G, Ben-Akiva M, Florian M, Grønland SE, van de Voort M (2005) Specification of a logistics model for Norway and Sweden European Transport Conference

13. de Jong G, Ben-Akiva M, Baak J (2010) Method report - Logistics model in the Swedish National Freight Model System. Technical report (Version 2)

14. de Jong G, Gunn H, Walker W (2004) National and international freight transport models: an overview and ideas for further development. Transp Rev 24(1):103-124

15. de Jong G, Vierth I, Tavasszy L, Ben-Akiva M (2012) Recent developments in national and international freight transport models within Europe. Transportation 40(2):347-371

16. Donnelly R, Meyburg A H, Shen H, Leachman R (2006) Evaluation of Practice Today. Freight Demand Modeling: Tools for Public-Sector Decision Making. TRB Conference Proceedings 40

17. Fischer M, Outwater M, Cheng LL, Ahanotu D, Calix R (2005) An Innovative Framework for Modeling Freight Transportation in Los Angeles County. Transport Research Board

18. Godet M (2000) The Art of scenarios and strategic planning: tools and pitfalls. Technol Forecast Soc Chang 65:3-22

19. Hesse M (2007) Mobilität im Zwischenraum. In: Schöller O, Canzler W, Knie A (2007). Handbook for Transport Policy, S. 279-300. Wiesbaden

20. Hesse M, Rodrigue JP (2004) The transport geography of logistics and freight distribution. J Transp Geogr 12:171-184

21. Janßen T, Vollmer R (2005) Entwicklung eines kleinräumigen Wirtschaftsverkehrsmodells. Technical report. Engineers Group for Transportation and Process Development

22. Jin Y, Williams I, Shahkarami M (2005) Integrated regional economic and freight logistics modelling: Results from a model for 
Trans-Pennine corridor, UK.. Technical report. Department for Transport. UK

23. Kille C, Schwemmer M (2012) Die Top 100 der logistik: marktgrößen, marktsegmente, und marktführer in der logistikdienstleistungswirtschaft 2012/2013. Deutscher VerkehrsVerlag, Hamburg

24. Klaus P, Kille C (2006) Die Top 100 der logistik: marktgrößen, marktsegmente und marktführer in der logistikdienstleistungswirtschaft 2006/2007. Deutscher VerkehrsVerlag, Hamburg

25. Klaus P, Krieger W (2008) Gabler lexikon logistik: management logistischer netzwerke und flüsse. GWV Fachverlag GmbH, Wiesbaden

26. Liedtke G (2006) An actor-based approach to commodity transport modelling. 5th Conference on Applied Infrastructure Research

27. Liedtke G (2009) Principles of micro-behaviour commodity transport modeling. Transp Res E 45(5):795-809

28. Mazzarino M (2012) Strategic scenarios of global logistics: what lies ahead for Europe? Eur Transp Res Rev 4(1):1-18

29. Meersman H, van de Voorde E (2013) The relationship between economic activity and freight transport. In: Moshe Ben-Akiva, Hilde Meersman, Eddy Van de Voorde: Freight Transport Modelling

30. Mest L (2011) Typologische Ordnung von Logistikstrategien und strukturen und ihre Integration in die Nachfragemodellierung des Güterwirtschaftsverkehrs. PhD thesis, Technical University of Dortmund

31. Mohammadian K, Kawamura K, Auld J (2011) A working demonstration of a mesoscale freight model for the Chicago Region. Final Report and User's Guide

32. NCHRP (2008) Forecasting Statewide Freight Toolkit. National Cooperative Highway Research Program. Transportation Research Board. Report 606. Washington, D.C. 2008

33. Outwater M, Smith C, Sana B, Chen J, Yoder S, Wies K, Lin J, Mohammadian K, Kawamura K (2012) Tour-based and Supply Chain Modeling for Freight. CMAP Pre-Symposium Webinar on Advanced Modeling

34. Pourabdollahi Z, Mohammadian K (2011) A conceptual framework for a behavioral freight transportation modeling system with logistics choices. Technical report. Department of Civil and Materials Engineering, University of Illinois, Chicago

35. Roorda MJ, Rinaldo C, McCabe S, Helen K (2010) A conceptual framework for agent-based modelling of logistics services. Transp Res E 46:18-31
36. Samimi A, Mohammadian K, Kawamura K (2010) Behavioral freight movement modeling. The 12 th International Conference on Travel Behaviour Research. Workshop W2: Behavioral Paradigms for Modeling Freight Travel Decision-Making

37. Sonntag H (2010) INTERIM - Integration in the intermodal goods transport of non EU states: Rail, inland/coastal waterway modes. Technical report. University of Applied Sciences, Wildau

38. Sonntag H, Meimbresse B (1999) Städtischer wirtschaftsverkehr und logistische knoten - wirkungsanalyse von verknüpfungen der güterverkehrsnetze auf den städtischen wirtschafts- und güterverkehr. Berichte der bundesanstalt für straßenwesen. Wirtschaftsverlag NW, Bergisch Gladbach

39. Tavasszy LA (2006) Freight modelling - An overview of international experiences. TRB Conference on Freight Demand Modelling: Tools for Public Sector Decision Making

40. Tavasszy LA (2010) SIMLE: Strategic Model for Integrated Logistics and Evaluations. Technical report. TNO Intro

41. Tavasszy LA, Davydenko I, Ruijgrok K (2009) The extended generalized cost concept and its application in Freight Transport and General Equilibrium Modeling. Bilateral Joint Seminar under agreement between NWO and JSPS

42. Tavasszy LA, de Jong G (2014) Modelling freight transport, 1st Edition

43. Tavasszy LA, Ruijgrok K, Davydenko I (2010) Incorporating logistics in freight transportation models: state of the art and research opportunities. 12th World Conference on Transport Research

44. Thaller C, Klauenberg J, Clausen U, Lenz B (2013) Charakterisierung logistischer Knoten mittels logistik-, verkehrsund betriebsspezifischer empirischer Daten. In: Clausen U, Thaller C (eds) Wirtschaftsverkehr 2013. Springer-Vieweg, Berlin, pp 49-73

45. Urban MS, Beagan D (2011) CMAP prototype mesoscale freight model. Peer Exchange Panel

46. Urban MS, Beagan D F, Fischer MJ (2012) A working demonstration of a mesoscale freight Model for the Chicago Region. Chicago

47. Vierth I (2011) Freight modelling and policy analysis in Sweden. CTS Seminar Freight Models. Technical report. Centre for Transport Studies (CTS) Seminar Freight Models, Stockholm

48. Vitasek K (2013) Supply chain management terms and glossary. Council of Supply Chain Management

49. Widlert S (2001) The Swedish model system for goods transport Samgods. Technical report. SAMPLAN Rapport

50. Winston C (1982) The demand for freight transportation - models and application. Transp Res A 17A(6):419-427 